\title{
Innate Immunity SNPs are Associated with Risk for Severe Sepsis after Burn Injury
}

\author{
Robert C. Barber, PhD; Ling-Yu E. Chang, BS; Brett D. Arnoldo, MD; Gary F. Purdue, MD; \\ John L. Hunt, MD; Jureta W. Horton, PhD; and Corinne C. Aragaki, PhD
}

\begin{abstract}
Objective: To analyze allelic association with clinical outcome in a cohort of burn patients.
Patients: Two hundred twenty-eight individuals with burns $\geq 15 \%$ total body surface area without significant non-burn related trauma who survived $>48$ hours post-admission were enrolled. One hundred fifty-nine of these patients were analyzed previously.
\end{abstract}

\begin{abstract}
Methods: Candidate polymorphisms within interleukin-I beta (IL-I $\beta$ ), interleukin-6 (IL-6), tumor necrosis factor alpha (TNF- $\alpha$ ), cellular differentiation marker I4 (CDI4) and toll-like receptor 4 (TLR4) were evaluated by logistic regression analysis for association with increased risk for severe sepsis (sepsis plus organ dysfunction or shock).
\end{abstract}

Results: After adjustment for age, burn size, ethnicity, gender and inhalation injury, alleles at TNF- $\alpha$ (308G, $\mathrm{p}=0.013)$, TLR4 (+896G, $\mathrm{p}=0.027)$, IL-6 (I74C, $\mathrm{p}=0.040)$ and CDI4 (I59C, $\mathrm{p}=0.047)$ were significantly associated with an increased risk for severe sepsis.

Conclusions: Carriage of variant alleles at immune response genes were associated with increased risk for severe sepsis after burn injury.

Keywords: Allelic association; Burns; CD I4; IL-6; Polymorphism; Sepsis; SNP; TLR4; TNF- $\alpha$

B mortality worldwide. Infectious complications, including sepsis, septic shock and sepsis-related organ failure, are common among patients with moderate to severe burn injuries. Sepsis accompanied by organ failure carries a $30-50 \%$ case-mortality rate, with surviving patients often requiring prolonged and costly medical care. ${ }^{1-5}$

Although intensive research has yielded greater understanding of the pathophysiological processes that follow burn injury and clinical factors that predispose burn victims to severe sepsis and septic shock, we are still unable to predict accurately those patients who are at increased risk for infectious complications. ${ }^{1}$ The lack of predictive value provided by demographic and clinical data, as well as a study of mortality risk in adopted children, ${ }^{6}$ suggests that genetic predisposition influences the risk for serious infection and outcome from severe injury. Knowledge of which genes and pathways are important in the host response to severe injury

and infection may provide insight into the molecular etiology of sepsis, facilitating the discovery of novel pharmacologic and therapeutic targets.

\section{Methods}

Patient Cohort

Under a protocol approved by the Institutional Review Boards of the University of Texas Southwestern Medical Center and Parkland Memorial Hospital, patients admitted to the burn intensive care unit at Parkland Memorial Hospital (Dallas, TX) with burns covering $\geq 15 \%$ of their total body surface area (TBSA) were prospectively enrolled between April 1999 and February 2005. In order to remove confounding variables unrelated to burn injury, individuals were excluded if they presented with significant non-burn related trauma (injury severity score $\geq 16$ ), traumatic or anoxic brain injury, or spinal cord injury, or if they failed to survive more than 48 hours post-admission. Sepsis was defined according to the American College of Chest Physicians and the Society for Critical Care Medicine consensus definitions. Severe sepsis

Received: June 20, 2006

Revised: October 17, 2006

Accepted: October 19, 2006
Grant Support: NIGMS grant number 5P50GM02I68I-40 
Table 1. Summary statistics for demographic variables and clinical outcomes following burn injury.

\begin{tabular}{|c|c|}
\hline Variable $(n=228)$ & Median/count ${ }^{1}$ \\
\hline Age (years) & $35(21-48)$ \\
\hline Male gender & $172(75 \%)$ \\
\hline $\begin{array}{l}\text { Ethnicity } \\
\text { Caucasian } \\
\text { Hispanic } \\
\text { African American } \\
\text { Other }\end{array}$ & $\begin{array}{c}129(56 \%) \\
51(22 \%) \\
41(18 \%) \\
7(4 \%)\end{array}$ \\
\hline Percent of total body surface area burned & $33(23-49)$ \\
\hline Percent of total body surface area full thickness burn & $18(9-38)$ \\
\hline $\begin{array}{l}\text { Burn mechanism } \\
\text { Flame } \\
\text { Scald } \\
\text { Electrical } \\
\text { Other }\end{array}$ & $\begin{array}{c}188(82 \%) \\
22(10 \%) \\
12(5 \%) \\
6(3 \%)\end{array}$ \\
\hline Inhalation injury & $55(24 \%)$ \\
\hline Died & $40(18 \%)$ \\
\hline Intensive care unit length of stay (days) & $16(4-32)$ \\
\hline Total length of stay (days) & $27(16-48)$ \\
\hline Duration of mechanical ventilation (days) & $10(0-22)$ \\
\hline
\end{tabular}

${ }^{1}$ Continuous data are presented as medians $\left(25^{\text {th }}-75^{\text {th }}\right.$ percentiles). Categorical data are presented as number of patients (percentages).

was defined as sepsis temporally accompanied by the need for intravenous vasopressor drug support (excluding dopamine at $\leq 5 \mu \mathrm{g} / \mathrm{kg} / \mathrm{min}$ ) to maintain blood pressure (despite adequate fluid resuscitation), along with the presence of perfusion abnormalities or metabolic acidosis $(\mathrm{pH} \leq 7.30)$ or the development of organ failure. Sepsis-related organ failure was defined as assignment of a Marshall organ dysfunction score of $\geq 3$ (failure) in one or more organs (lung, kidney, liver or blood) within 24 hours prior to or 48 hours following a diagnosis of sepsis. ${ }^{7}$

\section{DNA Isolation and Genotyping}

Venous blood samples were collected in EDTA, and genomic DNA was isolated by standard protocols. ${ }^{8}$ Genotypes were determined by pyrosequencing ${ }^{9}$ and TaqMan $^{\circledR}$ assays (Applied Biosystems, Inc., Foster City, CA). Details regarding genotyping methods have been published previously. ${ }^{10}$

\section{Data Analysis}

Data were analyzed with SPSS 14.0 statistical software (SPSS, Chicago, IL.). Categorical variables were compared using a chi-square test, and continuous data were analyzed by the Mann-Whitney $U$ test. Multivariate logistic regression was used to simultaneously evaluate carriage of variant alleles as risk factors for severe sepsis in the context of demographic variables (age, ethnicity and gender) and injury characteristics (burn size and inhalation injury). Exact p-values are reported for all analyses where $\mathrm{p}>0.001$.

\section{Results}

Demographics and Clinical Outcomes

Demographic variables, injury characteristics and clinical outcomes are presented in table 1. The patient cohort was relatively young (median age $=35)$, primarily male $(75 \%)$ and mostly Caucasian (56\%). Forty (18\%) of the 228 patients died. Major burn causes were flame (82\%), scald (10\%) and electrical (5\%). Fifty-five (24\%) patients developed severe sepsis, defined as sepsis complicated by organ dysfunction or septic shock. Pneumonia was the primary focus in $81 \%$ of patients with infection. Patients had relatively few co-morbid medical conditions. Alcohol abuse (43/228, 19\%), hypertension $(31 / 228,13 \%)$ and peripheral cardiovascular disease $(20 / 228,9 \%)$ were most common. Pre-existing liver, lung and renal disease were rare $(<3 \%)$.

Association between Single Nucleotide Polymorphisms (SNP) and Severe Sepsis Risk after Burn Injury

We evaluated allelic associations in the context of other potential risk factors by multivariate logistic regression analysis. After adjustment for age, ethnicity, gender, burn size and inhalation injury, variant alleles at tumor necrosis factor-alpha (TNF- $\alpha$ ), toll-like receptor 4 (TLR4), interleukin-6 (IL-6) and cellular differentiation marker 14 (CD14) were significantly 
Table 2. Risk factors for the development of severe sepsis after burn injury following adjustment for multiple factors.

\begin{tabular}{lccc}
\hline Variable $(\mathbf{n = 2 2 8})$ & Odds Ratio & 95\% Cl Odds Ratio & P-value \\
\hline Age & 1.010 & $0.991-1.028$ & 0.305 \\
Full-thickness burn size & 1.025 & $1.011-1.040$ & 0.001 \\
Gender (female) & 1.726 & $0.813-3.662$ & 0.155 \\
Inhalation injury & 2.714 & $1.246-5.912$ & 0.012 \\
Race/ethnicity & 1.197 & $0.828-1.729$ & 0.339 \\
CD14 -159C & 1.668 & $1.007-2.763$ & 0.047 \\
IL-1 $\beta$-31C & 1.272 & $0.593-2.726$ & 0.537 \\
IL-6 -174C & 2.250 & $1.037-4.884$ & 0.040 \\
TNF- $\alpha$-308A & 2.602 & $1.229-5.512$ & 0.013 \\
TLR4 $+896 G$ & 2.943 & $1.131-7.660$ & 0.027 \\
\hline
\end{tabular}

Odds ratios were determined by multivariate logistic regression. Age and full thickness burn size were analyzed as continuous variables. The odds ratios listed are for each additional year of age or each $1 \%$ increase in burn size. Race/ethnicity included the same categories as in table 1: Caucasian ( $n=129)$, Hispanic $(n=51)$, African-American $(n=41)$ and other $(n=7)$.

associated with an increased risk for severe sepsis. Adjusted odds ratios $(\mathrm{aOR})$ were $2.60(95 \%$ confidence interval $[\mathrm{CI}]=$ $1.23-5.51), 2.94(95 \% \mathrm{CI}=1.13-7.66), 2.25(95 \% \mathrm{CI}=1.04-4.88)$, and $1.67(95 \% \mathrm{CI}=1.01-2.76)$ for the TNF- $\alpha 308 \mathrm{~A}$, TLR4 $+896 \mathrm{G}$, IL-6 174C, and CD14 159C alleles, respectively (table $2)$. The IL-1 $\beta$-31 SNP was not significantly associated with severe sepsis risk $(\mathrm{p}=0.537)$. Age and burn size were analyzed as continuous variables. Odds ratios represented the risk associated with each increased year of age or percent burn size. Clinical factors that were significantly associated with increased risk included inhalation injury $(\mathrm{aOR}=2.71,95 \%$ $\mathrm{CI}=1.25-5.91, \mathrm{p}=0.012)$ and full-thickness ( $3^{\text {rd }}$ degree) burn size $(\mathrm{aOR}=1.03,95 \% \mathrm{CI}=1.01-1.04, \mathrm{p}=0.001)$. Age, ethnicity, gender and pre-existing medical conditions did not significantly affect risk for severe sepsis (table 2).

\section{Discussion}

These results provide further evidence that genetic polymorphisms within innate immunity loci are associated with an increased risk for severe sepsis after burn injury. While there has been recent controversy regarding the validity of genetic association data, confidence in our results was strengthened by independent evidence that our candidate SNPs had functional relevance. That is to say, alternate alleles at these SNPs seem to impact protein abundance or function.

For example, studies have suggested that altered TLR4 signaling plays a role in bacterial resistance, as well as the development of sepsis and septic shock. ${ }^{11-14}$ TLR4 is a trans-membrane protein which initiates a signaling cascade that triggers an innate immune response to endotoxin. ${ }^{15,16} \mathrm{~A}$ nonsynonymous substitution of guanine in place of adenine $(\mathrm{A} \rightarrow \mathrm{G})$ occurs at nucleotide +896 of the human TLR4 mRNA. This transition mutation precipitates substitution of asparagine with glycine at amino acid residue 299 within the extracellular domain of the protein. Carriers of the G-allele exhibit reduced lipopolysaccharide (LPS) responsiveness, increased risk for septic shock and greater susceptibility to gram-negative sepsis. $14,17,18$ Furthermore, transient transfection experiments in THP-1 cells indicated that the 299Gly allele was able to disrupt TLR4 signaling. ${ }^{18}$ Importantly, adenoviral transfection of wild type TLR4 was able to rescue LPS-responsiveness in airway epithelial cells and alveolar macrophages derived from individuals with TLR4 mutations. ${ }^{18}$ Finally, associations between altered TLR4 signaling and increased susceptibility or poor outcome have been observed in several inflammatory disease states. ${ }^{19-21}$

CD14 initiates a response to Gram-negative organisms by binding bacterial LPS. Physical contact between CD14-bound LPS, MD-2 and TLR4 initiates signal transduction within macrophages. ${ }^{22-24}$ A cytosine to thymine $(\mathrm{C} \rightarrow \mathrm{T})$ substitution at nucleotide 159 alters $\mathrm{Sp} 1$ nuclear protein binding to the CD14 promoter, with higher constitutive and LPS-induced transcription rates for the T-allele. ${ }^{25}$ The phenotypic impact of this polymorphism is uncertain. One study identified an association between this SNP and risk for myocardial infarction, but a second study did not. ${ }^{26,27}$ Findings have also been conflicting in patients with severe sepsis, with some studies observing no association and another finding a relationship between the T-allele and death from sepsis. ${ }^{17,28,29}$

TNF- $\alpha$ has been demonstrated to play a major role in the pathogenesis of sepsis and its complications after burn injury. ${ }^{30-33}$ Furthermore, there is evidence that a guanine to adenine substitution $(\mathrm{G} \rightarrow \mathrm{A})$ at nucleotide -308 within the TNF- $\alpha$ promoter affects transcriptional regulation. ${ }^{34,35}$ Carriage of the A-allele at this position has been associated with altered transcription and increased risk for infectious and 
inflammatory diseases in a number of clinical settings, including acute graft rejection following renal transplantation, sepsis among trauma patients, acute malaria and death from meningococcal disease. ${ }^{34,36-38}$

IL-6 is known to be important to many cellular responses. Its functional profile includes pro- and anti-inflammatory activities, regulation of T-cell activation, induction of antibody production, activation of coagulation and stimulation of hematopoiesis. ${ }^{39}$ Genetic variants within the promoter region have been shown to regulate IL-6 production, and may therefore influence the activity of IL-6 in vivo. ${ }^{40-42}$ A guanine to cytosine $(\mathrm{G} \rightarrow \mathrm{C})$ substitution at nucleotide -174 of the IL-6 promoter has been reported to affect gene transcription and has been associated with a number of conditions in which inflammation is considered to play a role. $21,43,44$

Allelic associations with severe sepsis were evaluated previously for 159 of the 228 patients described in this report. 10 The present study included patients with $\geq 15 \%$ TBSA burns, compared to patients with $\geq 20 \%$ burns in the previous analysis. Data from the initial investigation generally agreed with the current results, although several interesting differences were apparent. Both studies indicated full-thickness burn size and allele-carriage at TNF- $\alpha$ and TLR4 were important risk factors. In the previous report, inhalation injury was not significantly associated with severe sepsis risk, while in the current analysis, inhalation injury was a strongly associated risk factor $(p=0.012)$. Age and gender exhibited the opposite pattern. Both were significantly associated with increased risk in the original study but not in the current report. In contrast to the original investigation, the analyses we present here showed that carriage of IL-6 -174C and CD14 -159C alleles was significantly associated with increased severe sepsis risk $(p=0.040$ and 0.047 , respectively). Finally, odds ratios for risk alleles at TNF- $\alpha$ and TLR4 were considerably higher in the initial report than those we report here (TNF- $\alpha, 4.5$ vs 2.6; TLR4, 6.4 vs 2.9). Although if the lower limits of the $95 \%$ CI for the odds ratios are compared, the difference is much less dramatic (TNF- $\alpha$, 1.7 vs 1.2 ; TLR $4,1.8$ vs 1.1 ).

These differences are likely to be the result of larger sample size and subsequently increased statistical power in the current report. Narrower 95\% CI for the odds ratios reported in the present study support this explanation. However, it is also possible that there was some systematic difference in the 69 additional patients that were included in the present study.

It is possible that reducing the minimum total burn size for inclusion in the study from $20 \%$ to $15 \%$ TBSA affected the outcome by allowing inclusion of a radically different patient group. However, this seems unlikely, since only eight of 228 patients had $<20 \%$ TBSA burns, and these cases were clinically unremarkable. To investigate the additional patients further, we compared characteristics of the originally reported sample of 159 patients to the additional group of 69 patients (table 3). As expected, adjustment of eligibility criteria to include patients with smaller burns resulted in smaller median total and full-thickness burn size for the additional group of patients. Median age, gender distribution and rate of severe sepsis were roughly equivalent between the two groups. The mortality rate was higher among the more recent group of patients $(21 \% \mathrm{vs}$ $16 \%$ ) as were frequencies of the TNF- $\alpha$ and TLR4 risk alleles. Unexpectedly, given the increased incidence of mortality, inhalation injury and carriage of the CD14 C-allele were less frequent among recently enrolled patients.

We still do not know all the genetic and environmental factors that influence severe sepsis risk after burn injury. Because we are unable to adjust for these unknown risk factors, some groups of patients may appear to have spurious results with respect to known risk factors. This effect is expected to be most pronounced among small groups of patients, demonstrating the essential nature of large sample sizes for accurate estimation of effect sizes. When large numbers of patients are evaluated, unmeasured variables tend to be evenly distributed across known risk factors and have a reduced impact on results.

\section{Conclusion}

This study provides additional evidence for associations between polymorphisms within innate immunity loci and an increased risk for severe sepsis after burn injury. In addition, when contrasted with an earlier examination of this patient population, these results illustrate the importance of sample size and statistical power in allelic association studies.

Table 3. Characteristics of the original 159 patients compared to the additional 69 patients included in the current study.

\begin{tabular}{lcccccccccc}
\hline Sample & Died & $\begin{array}{c}\text { Severe } \\
\text { sepsis }\end{array}$ & $\begin{array}{c}\text { Median } \\
\text { age }\end{array}$ & $\begin{array}{c}3^{\text {rd }} \\
\text { degree } \\
\text { burns }\end{array}$ & $\begin{array}{c}\text { Total } \\
\text { burn }\end{array}$ & $\begin{array}{c}\text { Male } \\
\text { Gender }\end{array}$ & $\begin{array}{c}\text { Inhalation } \\
\text { injury }\end{array}$ & $\begin{array}{c}\text { CD14 } \\
\text { C-allele }\end{array}$ & $\begin{array}{c}\text { TNF- } \alpha \\
\text { A-allele }\end{array}$ & $\begin{array}{c}\text { TLR4 } \\
\text { G-allele }\end{array}$ \\
\hline Original report (159) & $16 \%$ & $24 \%$ & 35 & $20 \%$ & $35 \%$ & $74 \%$ & $29 \%$ & $81 \%$ & $25 \%$ & $11 \%$ \\
Additional patients (69) & $21 \%$ & $23 \%$ & 35 & $15 \%$ & $29 \%$ & $76 \%$ & $22 \%$ & $74 \%$ & $32 \%$ & $13 \%$ \\
\hline
\end{tabular}

Age and gender were equivalent between the two groups. As is evident, the death rate was higher in the recently enrolled patients, despite lower incidence of severe sepsis and inhalation injury. In addition, total and $3^{\text {rd }}$ degree burn size was smaller in the more recent patient group. Although frequency of the CD14 risk allele was lower, risk alleles at both TNF- $\alpha$ and TLR4 were more common among recently enrolled patients. 


\section{References}

1. Angus DC, Wax RS. Epidemiology of sepsis: an update. Crit Care Med 2001;29:S109-S116.

2. Bone RC. Toward an epidemiology and natural history of SIRS (systemic inflammatory response syndrome) JAMA 1992;268:3452-3455.

3. Friedman G, Silva E, Vincent JL. Has the mortality of septic shock changed with time. Crit Care Med 1998;26:2078-2086.

4. O'Keefe GE, Hunt JL, Purdue GF. An evaluation of risk factors for mortality after burn trauma and the identification of gender-dependent differences in outcomes. J Am Coll Surg 2001;192:153-160.

5. Abraham E, Matthay MA, Dinarello CA, Vincent JL, Cohen J, Opal SM, Glauser M, Parsons P, Fisher CJ Jr, Repine JE. Consensus conference definitions for sepsis, septic shock, acute lung injury, and acute respiratory distress syndrome: time for a reevaluation. Crit Care Med 2000;28:232-235.

6. Sorensen TI, Nielsen GG, Andersen PK, Teasdale TW. Genetic and environmental influences on premature death in adult adoptees. N Engl J Med 1988;318:727-732.

7. Marshall JC, Cook DJ, Christou NV, Bernard GR, Sprung CL, Sibbald WJ. Multiple organ dysfunction score: a reliable descriptor of a complex clinical outcome. Crit Care Med 1995;23:1638-1652.

8. Miller SA, Dykes DD, Polesky HF. A simple salting out procedure for extracting DNA from human nucleated cells. Nucleic Acids Res 1988;16:1215.

9. Ahmadian A, Gharizadeh B, Gustafsson AC, Sterky F, Nyren P, Uhlen M, Lundeberg J. Single-nucleotide polymorphism analysis by pyrosequencing. Anal Biochem 2000;280:103-110.

10. Barber RC, Aragaki CC, Rivera-Chavez FA, Purdue GF, Hunt JL, Horton JW. TLR4 and TNF-alpha polymorphisms are associated with an increased risk for severe sepsis following burn injury. J Med Genet 2004;41:808-813.

11. Chapes SK, Mosier DA, Wright AD, Hart ML. MHCII, TLR4 and Nramp1 genes control host pulmonary resistance against the opportunistic bacterium Pasteurella pneumotropica. J Leukoc Biol 2001;69:381-386.

12. Ingalls RR, Lien E, Golenbock DT. Differential roles of TLR2 and TLR4 in the host response to Gram-negative bacteria: lessons from a lipopolysaccharide-deficient mutant of Neisseria meningitidis. J Endotoxin Res 2000;6:411-415.

13. Leveque G, Forgetta V, Morroll S, Smith AL, Bumstead N, Barrow P, Loredo-Osti JC, Morgan K, Malo D. Allelic variation in TLR4 is linked to susceptibility to Salmonella enterica serovar Typhimurium infection in chickens. Infect Immun 2003;71:1116-1124.

14. Lorenz E, Mira JP, Frees KL, Schwartz DA. Relevance of mutations in the TLR4 receptor in patients with gram-negative septic shock. Arch Intern Med 2002;162:1028-1032.

15. Smirnova I, Poltorak A, Chan EK, McBride C, Beutler B. Phylogenetic variation and polymorphism at the toll-like receptor 4 locus (TLR4). Genome Biol 2000;1:RESEARCH002.

16. Belvin MP, Anderson KV. A conserved signaling pathway: the Drosophila toll-dorsal pathway. Annu Rev Cell Dev Biol 1996;12:393-416.

17. Agnese DM, Calvano JE, Hahm SJ, Coyle SM, Corbett SA, Calvano SE, Lowry SF. Human toll-like receptor 4 mutations but not CD14 polymorphisms are associated with an increased risk of gram-negative infections. J Infect Dis 2002; 186:1522-1525.

18. Arbour NC, Lorenz E, Schutte BC, Zabner J, Kline JN, Jones M, Frees K, Watt JL, Schwartz DA. TLR4 mutations are associated with endotoxin hyporesponsiveness in humans. Nat Genet 2000;25:187-191.
19. Ferrand PE, Fujimoto T, Chennathukuzhi V, Parry S, Macones GA, Sammel M, Kuivaniemi H, Romero R, Strauss JF 3rd. The CARD15 2936insC mutation and TLR4 $896 \mathrm{~A}>\mathrm{G}$ polymorphism in African Americans and risk of preterm premature rupture of membranes (PPROM). Mol Hum Reprod 2002;8:1031-1034.

20. Schwartz DA. TLR4 and LPS hyporesponsiveness in humans. Int J Hyg Environ Health 2002;205:221-227.

21. Frantz S, Kobzik L, Kim YD, Fukazawa R, Medzhitov R, Lee RT, Kelly RA. Toll4 (TLR4) expression in cardiac myocytes in normal and failing myocardium. J Clin Invest 1999; 104:271-280.

22. Kitchens RL, Thompson PA, Viriyakosol S, O'Keefe GE, Munford RS. Plasma CD14 decreases monocyte responses to LPS by transferring cell-bound LPS to plasma lipoproteins. J Clin Invest 2001;108:485-493.

23. Poltorak A, Ricciardi-Castagnoli P, Citterio S, Beutler B. Physical contact between lipopolysaccharide and toll-like receptor 4 revealed by genetic complementation. Proc Natl Acad Sci U S A 2000;97:2163-2167.

24. Poltorak A, He X, Smirnova I, Liu MY, Van Huffel C, Du X, Birdwell D, Alejos E, Silva M, Galanos C, Freudenberg M, Ricciardi-Castagnoli P, Layton B, Beutler B. Defective LPS signaling in $\mathrm{C} 3 \mathrm{H} / \mathrm{HeJ}$ and $\mathrm{C} 57 \mathrm{BL} / 10 \mathrm{ScCr}$ mice: mutations in Tlr4 gene. Science 1998;282:2085-2088.

25. LeVan TD, Bloom JW, Bailey TJ, Karp CL, Halonen M, Martinez FD, Vercelli D. A common single nucleotide polymorphism in the CD14 promoter decreases the affinity of Sp protein binding and enhances transcriptional activity. J Immunol 2001;167:5838-5844.

26. Hubacek JA, Rothe G, Pit'ha J, Skodova Z, Stanek V, Poledne R, Schmitz G. C(-260) $\rightarrow$ T polymorphism in the promoter of the CD14 monocyte receptor gene as a risk factor for myocardial infarction. Circulation 1999;99:3218-3220.

27. Koch W, Kastrati A, Mehilli J, von Beckerath N, Schomig A. CD14 gene $-159 \mathrm{C} / \mathrm{T}$ polymorphism is not associated with coronary artery disease and myocardial infarction. Am Heart J 2002;143:971-976.

28. Hubacek JA, Stuber F, Frohlich D, Book M, Wetegrove S, Rothe G, Schmitz G. The common functional C(-159)T polymorphism within the promoter region of the lipopolysaccharide receptor CD14 is not associated with sepsis development or mortality. Genes Immun 2000;1:405-407.

29. Gibot S, Cariou A, Drouet L, Rossignol M, Ripoll L. Association between a genomic polymorphism within the CD14 locus and septic shock susceptibility and mortality rate. Crit Care Med 2002;30:969-973.

30. Marano MA, Fong Y, Moldawer LL, Wei H, Calvano SE, Tracey KJ, Barie PS, Manogue K, Cerami A, Shires GT, Lowry SF. Serum cachectin/tumor necrosis factor in critically ill patients with burns correlates with infection and mortality. Surg Gynecol Obstet 1990;170:32-38.

31. Drost AC, Burleson DG, Cioffi WG Jr, Jordan BS, Mason AD Jr, Pruitt BA Jr. Plasma cytokines following thermal injury and their relationship with patient mortality, burn size, and time postburn. J Trauma 1993;35:335-339.

32. Endo S, Inada K, Yamada Y, Kasai T, Takakuwa T, Nakae H, Kikuchi M, Hoshi S, Suzuki M, Yamashita H, Yoshida M. Plasma tumour necrosis factor-alpha (TNF-alpha) levels in patients with burns. Burns 1993;19:124-127.

33. Arslan E, Yavuz M, Dalay C. The relationship between tumor necrosis factor (TNF)-alpha and survival following granulocyte-colony stimulating factor (G-CSF) administration in burn sepsis. Burns 2000;26:521-524.

34. O'Keefe GE, Hybki DL, Munford RS. The G $\rightarrow$ A single nucleotide polymorphism at the -308 position in the tumor necrosis factor-alpha promoter increases the risk for severe sepsis after trauma. J Trauma 2002;52:817-825. 
35. Mira JP, Cariou A, Grall F, Delclaux C, Losser MR, Heshmati F, Cheval C, Monchi M, Teboul JL, Riche F, Leleu G, Arbibe L, Mignon A, Delpech M, Dhainaut JF. Association of TNF2, a TNF-alpha promoter polymorphism, with septic shock susceptibility and mortality: a multicenter study. JAMA 1999;282:561-568.

36. Knight JC, Udalova I, Hill AV, Greenwood BM, Peshu N, Marsh K, Kwiatkowski D. A polymorphism that affects OCT-1 binding to the TNF promoter region is associated with severe malaria. Nat Genet 1999;22:145-150.

37. Sankaran D, Asderakis A, Ashraf S, Roberts IS, Short CD, Dyer PA, Sinnott PJ, Hutchinson IV. Cytokine gene polymorphisms predict acute graft rejection following renal transplantation. Kidney Int 1999;56:281-288.

38. Nadel S, Newport MJ, Booy R, Levin M. Variation in the tumor necrosis factor-alpha gene promoter region may be associated with death from meningococcal disease. J Infect Dis 1996; $174: 878-880$

39. Tilg H, Dinarello CA, Mier JW. IL-6 and APPs: anti-inflammatory and immunosuppressive mediators. Immunol Today 1997; 18:428-432.

40. Brull DJ, Montgomery HE, Sanders J, Dhamrait S, Luong L, Rumley A, Lowe GD, Humphries SE. Interleukin-6 gene $-174 \mathrm{~g}>\mathrm{c}$ and $-572 \mathrm{~g}>\mathrm{c}$ promoter polymorphisms are strong predictors of plasma interleukin-6 levels after coronary artery bypass surgery. Arterioscler Thromb Vasc Biol 2001;21:1458-1463.

41. Fishman D, Faulds G, Jeffery R, Mohamed-Ali V, Yudkin JS, Humphries S, Woo P. The effect of novel polymorphisms in the interleukin-6 (IL-6) gene on IL-6 transcription and plasma IL-6 levels, and an association with systemic-onset juvenile chronic arthritis. J Clin Invest 1998;102:1369-1376.

42. Terry CF, Loukaci V, Green FR. Cooperative influence of genetic polymorphisms on interleukin 6 transcriptional regulation. J Biol Chem 2000;275:18138-18144.

43. Rauramaa R, Vaisanen SB, Luong LA, Schmidt-Trucksass A, Penttila IM, Bouchard C, Toyry J, Humphries SE. Stromelysin-1 and interleukin-6 gene promoter polymorphisms are determinants of asymptomatic carotid artery atherosclerosis. Arterioscler Thromb Vasc Biol 2000;20:2657-2662.

44. Hulkkonen J, Pertovaara M, Antonen J, Pasternack A, Hurme M. Elevated interleukin- 6 plasma levels are regulated by the promoter region polymorphism of the IL6 gene in primary Sjögren's syndrome and correlate with the clinical manifestations of the disease. Rheumatology (Oxford) 2001;40:656-661.

\section{Author Affiliations}

Robert C. Barber, PhD

Department of Surgery

University of Texas Southwestern Medical Center

Dallas, Texas USA

Ling-Yu E. Chang, BS

Department of Surgery

University of Texas Southwestern Medical Center

Dallas, Texas USA

Brett D. Arnoldo, MD

Department of Surgery

University of Texas Southwestern Medical Center

Dallas, Texas USA
Gary F. Purdue, MD

Department of Surgery

University of Texas Southwestern Medical Center

Dallas, Texas USA

John L. Hunt, MD

Department of Surgery

University of Texas Southwestern Medical Center

Dallas, Texas USA

Jureta W. Horton, PhD

Department of Surgery

University of Texas Southwestern Medical Center

Dallas, Texas USA

Corinne C. Aragaki, PhD

Divisions of Epidemiology and Biostatistics

University of Texas School of Public Health

Houston, Texas USA 